\title{
Validation of reference genes for quantitative expression analysis by real-time RT-PCR in Saccharomyces cerevisiae Marie-Ange Teste ${ }^{\dagger 1,2,3}$, Manon Duquenne ${ }^{\dagger 1,2,3,4}$, Jean M François ${ }^{1,2,3}$ and Jean-Luc Parrou*1,2,3
}

Address: ${ }^{1}$ CNRS, UMR5504, F-31400 Toulouse, France, ${ }^{2}$ INRA, UMR792 Ingénierie des Systèmes Biologiques et des Procédés, F-31400 Toulouse, France, ${ }^{3}$ Université de Toulouse; INSA, UPS, INP; LISBP, 135 Avenue de Rangueil, F-31077 Toulouse, France and ${ }^{4}$ Current address: Unité des Bactéries Lactiques et pathogènes Opportunistes, INRA - Centre de Recherche de Jouy-en-Josas, Domaine de Vilvert, 78352 Jouy-en Josas, France

Email: Marie-Ange Teste - Marie-Ange.Teste@insa-toulouse.fr; Manon Duquenne - manon.duquenne@jouy.inra.fr; Jean M François - fran_jm@insa-toulouse.fr; Jean-Luc Parrou* - Jean-Luc.Parrou@insa-toulouse.fr

* Corresponding author †Equal contributors

Published: 30 October 2009

BMC Molecular Biology 2009, 10:99 doi:10.1186/1471-2199-10-99

This article is available from: http://www.biomedcentral.com/147I-2199//0/99

(c) 2009 Teste et al; licensee BioMed Central Ltd.

This is an Open Access article distributed under the terms of the Creative Commons Attribution License (http://creativecommons.org/licenses/by/2.0), which permits unrestricted use, distribution, and reproduction in any medium, provided the original work is properly cited.

\begin{abstract}
Background: Real-time RT-PCR is the recommended method for quantitative gene expression analysis. A compulsory step is the selection of good reference genes for normalization. A few genes often referred to as HouseKeeping Genes (HSK), such as ACTI, RDNI 8 or PDAI are among the most commonly used, as their expression is assumed to remain unchanged over a wide range of conditions. Since this assumption is very unlikely, a geometric averaging of multiple, carefully selected internal control genes is now strongly recommended for normalization to avoid this problem of expression variation of single reference genes. The aim of this work was to search for a set of reference genes for reliable gene expression analysis in Saccharomyces cerevisiae.
\end{abstract}

Results: From public microarray datasets, we selected potential reference genes whose expression remained apparently invariable during long-term growth on glucose. Using the algorithm geNorm, ALG9, TAFIO, TFCI and UBC6 turned out to be genes whose expression remained stable, independent of the growth conditions and the strain backgrounds tested in this study. We then showed that the geometric averaging of any subset of three genes among the six most stable genes resulted in very similar normalized data, which contrasted with inconsistent results among various biological samples when the normalization was performed with ACTI. Normalization with multiple selected genes was therefore applied to transcriptional analysis of genes involved in glycogen metabolism. We determined an induction ratio of 100 -fold for GPHI and 20-fold for GSY2 between the exponential phase and the diauxic shift on glucose. There was no induction of these two genes at this transition phase on galactose, although in both cases, the kinetics of glycogen accumulation was similar. In contrast, SGAI expression was independent of the carbon source and increased by 3 -fold in stationary phase.

Conclusion: In this work, we provided a set of genes that are suitable reference genes for quantitative gene expression analysis by real-time RT-PCR in yeast biological samples covering a large panel of physiological states. In contrast, we invalidated and discourage the use of $A C T I$ as well as other commonly used reference genes (PDAI, TDH3, RDNI8, etc) as internal controls for quantitative gene expression analysis in yeast. 


\section{Background}

Real-time PCR technology has recently reached a level of sensitivity, accuracy and practical simplicity allowing its use as a routine bioinstrumentation for pathogen detection, single nucleotide polymorphism and gene expression analysis [1-4]. In particular for the latter application, several controls are needed to ensure the integrity of each step along the process [5] and therefore, to obtain reliable and accurate results. This process includes RNA extraction (yield, integrity, DNA contamination), efficiency of the reverse transcription and PCR steps, amount of RNA added into the reaction, etc. While the quantitative RTPCR is technically robust, the normalization procedure to correct sample-to-sample variation remains a critical and challenging problem of this method [1,4,6,7]. Several procedures have been suggested based on physical parameters, such as volume or cell number, but these methods are either impractical or unreliable due to the heterogeneity of biological samples. Some authors favour an internal control strategy, which uses an alien RNA molecule that is artificially incorporated into the biological sample [7]. As an example, Liu \& Slininger proposed a set of universal external RNA calibrators for microbial mRNA expression analysis [8]. In spite of these initiatives, the most common practice is to normalize to either total RNA amount, ribosomal RNA or to a single internal reference gene termed HouseKeeping gene (HSK). Several mathematical models have been developed that calculate the "relative" mRNA expression changes of a target gene with respect to an

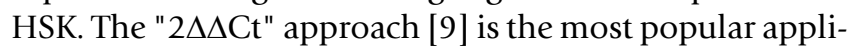
cation in quantitative RT-PCR, but it assumes optimal and identical PCR efficiencies of target and reference genes. Violation of this rule results in a systematic bias that either underestimates or overestimates the initial copy numbers. This problem can be bypassed by adjusting for PCR efficiency, which can be estimated using many approaches [10-12] that can be separated into three groups [12]: serial dilutions, individual graph analysis based on the rate of fluorescence accumulation within the exponential region, or mathematical model fitting. Whatever the method employed for determining the PCR efficiency, accurate relative quantification implies that the expression of the reference gene is perfectly stable in the sample set.

It is empirically assumed that housekeeping genes fulfil the criterion of unregulated expression independent of the experimental condition. However, some evidence shows that these genes are regulated to some extent, reinforcing the idea that there is no universal reference gene whose expression level remains constant whatever the conditions [2]. Since even small variations of an internal control could lead to non-reliable expression data, it is critical to validate that the expression of reference genes is stable prior to their use for normalization in real time RTPCR analysis. To overcome the "circular problem" of eval- uating the expression stability of a candidate gene if no reliable measure is available to normalize the candidate [13], Vandesompele and colleagues [14] developed a statistical algorithm termed geNorm. Their strategy relied on (i) a careful selection of a set of genes that display minimal variation across different biological conditions, and (ii) normalization of the genes of interest to the geometric mean of a minimal, albeit optimal number of the selected genes. The strength of using geometric averaging is in smoothing the individual variation of the expression value of a single reference gene, which can lead to large errors of normalized data in samples of interest [14]. Other statistical algorithms were also proposed, e.g. Bestkeeper [15], which allows including up to ten genes of interest in the analysis, or Normfinder [13] that is apparently less sensitive toward coregulation of the candidate reference genes.

Real-time RT-PCR is commonly used to validate microarray-generated data $[16,17]$. ACT1 and RDN18 are among the most frequently used reference genes in $S$. cerevisiae studies, because the expression of these genes has been considered relatively stable under the conditions investigated. However, only two recent papers showed the stability of ACT1 expression and some other standard reference genes to normalize the expression of genes involved in central carbon metabolism during short-term glucose pulse [18], or during the rehydration process in active dry yeast [19]. With the notable exception of these works, we could not find any study dedicated to the selection and validation of suitable reference genes in S. cerevisaie, contrary to other fungal models such as the pathogenic yeast Candida albicans [20], and the fungi Metarhizium anisopliae [21] and Aspergillus niger [22]. Therefore, the purpose of the present work was to identify a robust set of reference genes for growth phase-related mRNA profiling in the yeast Saccharomyces cerevisiae. From public microarray datasets, we selected a set of potential reference genes that exhibited minimal variation among various conditions. The most stable subset of internal controls, which gave rise to a robust normalization factor, was then applied to quantify expression of genes involved in glycogen metabolism in response to changing growth conditions, and in a mutant defective in TPS1 which encodes the trehalose6P synthase subunit [23].

\section{Results \\ Sampling}

Cell samples were regularly harvested from the yeast cultures, and only samples from key physiological states were selected and used for mRNA quantification by real time RT-PCR assays (Figure 1 and Additional files 1 and 2). These physiological states were defined from the macrokinetic growth parameters and reserve carbohydrates profiles as follows: the exponential - respiro fermentative- 

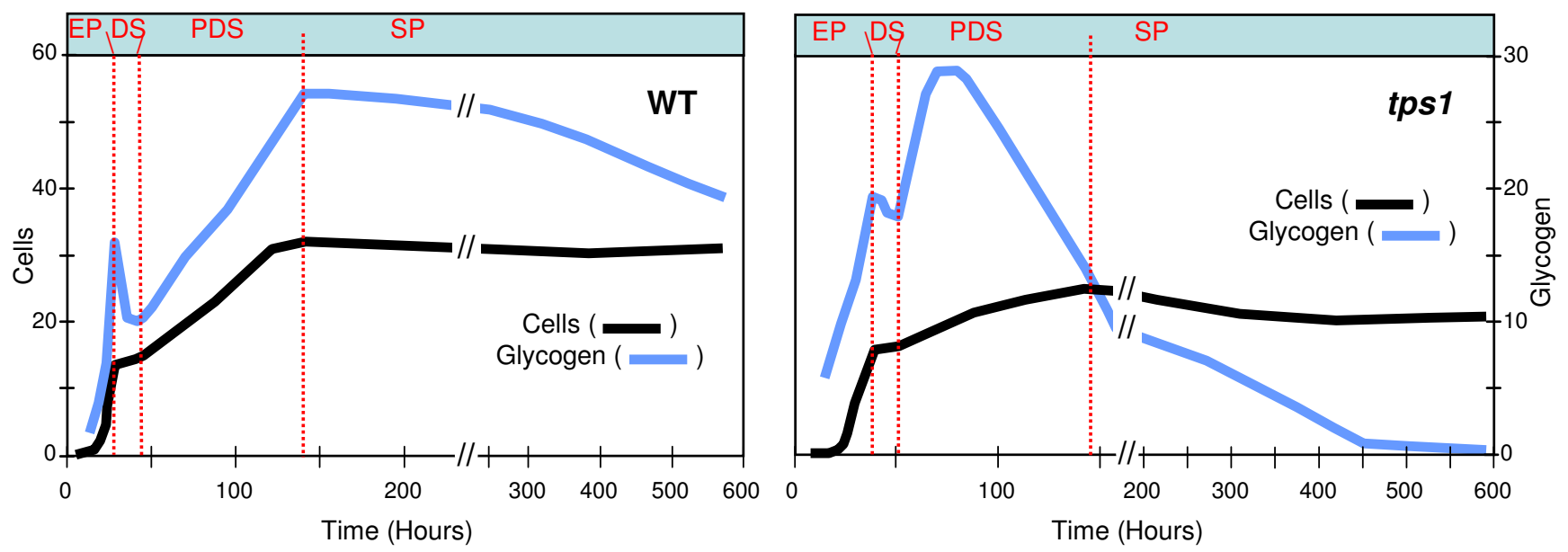

Figure I

Schematic view of growth characteristics of a WT strain and its tps I derivative. Growth (cells) and glycogen profiles during cultures of CEN.PK strains on galactose. WT (left, set D from Figure 2) and tps I (right, set H from Figure 2). EP, Exponential Phase; DS, Diauxic Shift; PDS, Post-Diauxic Shift; SP, Stationary Phase. Original data and sampling numbering can be found in the Additional files. Cells ( $\left.\mathrm{OD}_{600}\right)$, Glycogen ( $\mu \mathrm{g}$ eq.glucose/OD unit).

phase (EP); the diauxic shift (DS), which corresponds to the time when the sugar has just been exhausted from the medium while glycogen shows a transient peak of accumulation; the post-diauxic or purely respiratory phase (PDS), which corresponds to the re-assimilation of fermentation products and to a second phase of glycogen accumulation; and finally, the stationary phase (SP) when cells are starved for carbon nutrient. Contrary to the wild type strain behaviour, the tps1 mutant significantly mobilized glycogen during the PDS phase, and consequently more samples were taken up during this period to better characterize the physiological state of this mutant in this growth phase (see also additional file 2 for details of the sampling). In total, we carried out six independent yeast cultures (Figure 2). The wild type KT strain was grown on glucose (sample set $\mathrm{B}$ ) as the basic and reference growth condition [24]. It was also cultivated on galactose (set $\mathrm{C}$ ), which was used as the growth control condition for tps 1 mutant since this mutant strain cannot grow on glucose [25]. Finally, cultures on galactose of the CEN.PK strain and the corresponding tps1 mutant were made in duplicates (sets D \& E for the wild type CEN.PK and sets H \& I for the tps1 mutant).

\section{Expression level and stability of candidate reference genes} As stated in the introduction, accurate normalization requires reference genes whose expression changes are negligible under the investigated conditions. Candidate genes were therefore identified using public microarray datasets from De Risi et al [26] and Gasch et al [27], because the culture conditions reported in these studies were the closest to our experimental setup. We selected eight potential reference genes based on the stability of their expression during growth on glucose (genes highlighted in bold in Table 1), taking care that these genes belong to different functional categories to minimize the risk of coregulation. The remaining genes listed in Table 1 , i.e. ACT1, PDA1, RDN18, IPP1 and TDH3, were also included in the list since they are traditionally used as single reference genes in expression studies by Northern blots or real time RT-PCR.

Transcription profiling using real-time RT-PCR assays was then performed with these 13 candidate genes, in samples from the 6 cultures. We first analyzed transcript abundance of these genes in the different samples by direct comparison of their cycle threshold $(\mathrm{Ct})$, assuming equal $\mathrm{Ct}$ for equal transcript number since all RT-PCR reactions were performed with equal quantity of total RNA. As can be seen in Figure 3, most of the selected genes presented Ct values that spanned from 20 to 30 cycles, while Ct values from RDN18 and TDH3 were clearly lower. For RDN18, these values centered around 8 cycles with a very low dispersion. The glycolytic gene TDH3 was also highly expressed as indicated by $\mathrm{Ct}$ values around 17 cycles, but it exhibited rather high dispersion over the growth phases and culture conditions as indicated by large whiskers of the box and many outliers. The $\mathrm{Ct}$ of the remaining selected genes showed a reasonable dispersion, with expression levels of ALG9, KRE11, TAF10, TFC1 and UBC6 exhibiting smaller variation than that of ACT1, HEM2, IPP1 or PDA1. 


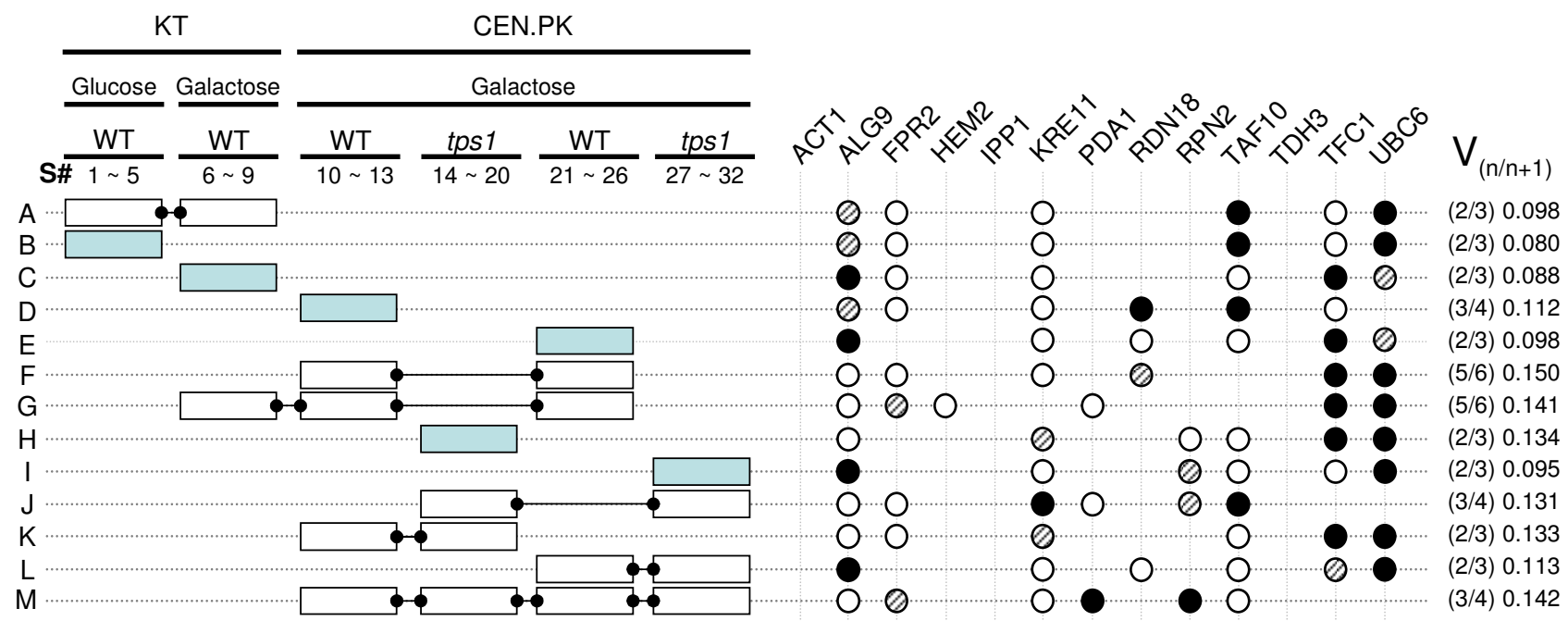

\section{Figure 2}

Sample sets and Ranking of candidate reference genes as calculated by geNorm. Left panel: Independent cultures (illustrated by the boxes) were carried out: Wild type KT strain on glucose (sample set B) and galactose (set C); Wild type CEN.PK (set D \& set E as independent cultures) and its tps I derivative strain (set $\mathrm{H}$ \& set I as independent cultures), on galactose. Sampling [S\#] was performed all along the cultures with a posteriori selection and analysis of 4 to 7 RNA samples representative of different physiological states (e.g. samples I to 5 for growth of the KT strain on glucose; see Additional file I). Expression data from one culture (e.g. set $B /$ ) or from several cultures (connector between boxes, e.g. set $A /$ that includes samples from sets $B$ \& $C$ together) were then analyzed with geNorm (A $\sim$ M sample sets). Right panel: Synthetic overview of ranking of the candidate reference genes according to their expression stability, and determination of the optimal number of genes used for normalization. The 2 most stable genes (black circle), the third (dashed circle) and the following 3 best reference genes (empty circle). Pair-wise variation $\left(\mathrm{V}_{n / n+1}\right)$ between $N F_{n}$ and $N F_{n+1}(N F$ : normalization factor; n: number of genes used for NF calculation). Right Column: pair-wise variation value below the threshold 0.15 , which means that $n$ genes might be sufficient for NF calculation (i.e. 2 genes for set "A"). See additional file 3 for overall stability under the standard geNorm output format.

These raw Ct data were then analyzed using geNorm to identify the most suitable candidate genes. For each independent culture (e.g. sample set B, Figure 2 left panel), or pool of several cultures (e.g. set A that combined samples from cultures $\mathrm{B} \& \mathrm{C}$ ), the 13 genes were ranked according to their gene expression stability measure " $\mathrm{M}$ " (Figure 2, right panel, and additional file 3 ). All genes presented an $M$ value below 1.5, which is the default limit for acceptable expression stability as defined by Vandesompele et al [14]. Another advantage of geNorm is to provide the optimal number of reference genes required for accurate normalization. This number is obtained by calculating the Pairwise variation values $\left(\mathrm{V}_{(\mathrm{n} / \mathrm{n}+1)}\right)$ between each combination of sequential normalization factors (NF) (Figure 2, right column). Vandesompele and coworkers [14] recommended a cut-off value at 0.15 , below which the inclusion of an additional gene does not result in a significant improvement of the normalization. According to this criterion, TAF10 and UBC6 turned out to be sufficient as internal controls to normalize expression levels from samples taken from growth on glucose (set $\mathrm{A}, \mathrm{V}_{2 / 3}=0.098$ ), whereas 5 genes were required for normalizing gene expression from the data sets $\mathrm{F}$ and $\mathrm{G}\left(\mathrm{V}_{5 / 6}=0.150\right.$ and
0.141 , respectively). According to the recommendation of Vandesompele et al [14], we always used a minimum of three of the most stably expressed genes to calculate the normalization factor. From this analysis, ACT1, IPP1 and TDH3 were excluded from the set of selected genes for normalization as they always ranked among the worst candidates. In contrast, ALG9, TAF10, TFC1, UBC6 and to a lesser extent KRE11 turned out to be the most stable genes in the culture conditions tested in this study (Figure 2 right panel, additional file 3 ).

To further support this conclusion and the suitability of this set of genes to serve as a reference in a broader panel of experimental conditions, we examined gene stability of these candidate reference genes by using data from the entire microarray datasets from the SGD server (approx. 30 experiments), which altogether correspond to several hundred different experimental conditions. As can be seen in Figure 4, genes like ALG9, TAF10, TFC1, UBC6 presented a significantly higher number of experiments with a $\log 2$ ratio close to zero as compared to ACT1. This microarray survey analysis indicated that our initially selected genes exhibited very little expression change over 
Table I: List of candidate reference genes and genes of interest

\begin{tabular}{|c|c|c|c|}
\hline Name & Molecular Function (SGD curated)/Biological process & Primer sequence & Eff \\
\hline \multicolumn{4}{|c|}{ Candidate reference genes } \\
\hline ACTI & $\begin{array}{c}\text { Structural constituent of cytoskeleton/Cell polarization, endocytosis, } \\
\text { and other cytoskeletal functions }\end{array}$ & $\begin{array}{l}\text { F:ATTATATGTTTAGAGGTTGCTGCTTTGG } \\
\text { R:CAATTCGTTGTAGAAGGTATGATGCC }\end{array}$ & 94 \\
\hline ALG9 & Mannosyltransferase activity/Protein amino acid glycosylation & $\begin{array}{c}\text { F:CACGGATAGTGGCTTTGGTGAACAATTAC } \\
\text { R:TATGATTATCTGGCAGCAGGAAAGAACTTGGG }\end{array}$ & 93 \\
\hline FPR2 & Membrane-bound peptidyl-prolyl cis-trans isomerase activity/Unknown & $\begin{array}{c}\text { F:TCTTTATTAGAATCGGGAACTGTATTTGACTC } \\
\text { R:AATGACGCCTGGGACACCTCTTTC }\end{array}$ & 89 \\
\hline HEM2 & Porphobilinogen synthase activity/Heme biosynthesis & $\begin{array}{c}\text { F:TTCCGCTATTCATCTCCGATAATCCAG } \\
\text { R:ACAGACATCGCAAATAATATACAGTTCAGG }\end{array}$ & 95 \\
\hline IPPI & Inorganic diphosphatase activity/Phosphate metabolic process & $\begin{array}{c}\text { F:CCCAATCATCCAAGACACCAAGAAGG } \\
\text { R:AGCAATAGTTTCACCAATTTCCAACACATC }\end{array}$ & 90 \\
\hline KREII & Unknown/ER to Golgi vesicle-mediated transport & $\begin{array}{c}\text { F:AACTGGTTCTGTTACCCAAATCAACTCAAC } \\
\text { R:AACGCTTCAATGTGACTTCTGTTTCCC }\end{array}$ & 86 \\
\hline PDAI & Pyruvate dehydrogenase activity/Pyruvate metabolism & $\begin{array}{c}\text { F:ATTTGCCCGTCGTGTTTTGCTGTG } \\
\text { R:TATGCTGAATCTCGTCTCTAGTTCTGTAGG }\end{array}$ & 93 \\
\hline RDN/8 & Sstructural constituent of ribosome/Translation & $\begin{array}{l}\text { F:AACTCACCAGGTCCAGACACAATAAGG } \\
\text { R:AAGGTCTCGTTCGTTATCGCAATTAAGC }\end{array}$ & 93 \\
\hline RPN2 & Protein binding, bridging/Ubiquitin-dependent protein catabolic process & $\begin{array}{l}\text { F:GCGGATACAGGCACATTGGATACC } \\
\text { R:TGTTGCTACCTTCTCTACCTCCTTACC }\end{array}$ & 101 \\
\hline TAFIO & $\begin{array}{c}\text { RNA Pol II transcription factor activity/Transcription initiation and } \\
\text { chromatin modification }\end{array}$ & $\begin{array}{c}\text { F:ATATTCCAGGATCAGGTCTTCCGTAGC } \\
\text { R:GTAGTCTTCTCATTCTGTTGATGTTGTTGTTG }\end{array}$ & 96 \\
\hline $\mathrm{TDH} 3$ & $\begin{array}{l}\text { Glyceraldehyde-3P dehydrogenase (phosphorylating) activity/Glycolysis } \\
\text { \& Gluconeogenesis }\end{array}$ & $\begin{array}{l}\text { F:CGGTAGATACGCTGGTGAAGTTTC } \\
\text { R:TGGAAGATGGAGCAGTGATAACAAC }\end{array}$ & 91 \\
\hline TFCI & $\begin{array}{l}\text { RNA Pol III transcription factor activity/Transcription initiation on Pol III } \\
\text { promoter }\end{array}$ & $\begin{array}{c}\text { F:GCTGGCACTCATATCTTATCGTTTCACAATGG } \\
\text { R:GAACCTGCTGTCAATACCGCCTGGAG }\end{array}$ & 91 \\
\hline UBC6 & Ubiquitin-protein ligase activity/ER-associated protein catabolic process & $\begin{array}{c}\text { F:GATACTTGGAATCCTGGCTGGTCTGTCTC } \\
\text { R:AAAGGGTCTTCTGTTTCATCACCTGTATTTGC }\end{array}$ & 84 \\
\hline \multicolumn{4}{|c|}{ Genes of interest (GOIs) in glycogen metabolism } \\
\hline GPHI & Glycogen phosphorylase activity/Glycogen catabolic process & $\begin{array}{l}\text { F:ACAAAACTCAGCAGAAATTCACCACAAG } \\
\text { R:CAAGACGACCTAGACCACCATTACC }\end{array}$ & 90 \\
\hline GSY2 & Glycogen synthase activity/Glycogen biosynthetic process & $\begin{array}{l}\text { F:TGCCCAGTATAAAGACCATTACCACTTGATAGG } \\
\text { R:GCACCTTCAATCAGCCACCTCCCATAAAC }\end{array}$ & 86 \\
\hline SGAI & glucan I,4-alpha-glucosidase activity/Glycogen catabolic process & $\begin{array}{l}\text { F:TCCAAACGGATATTTCCTGGGTGGTACTGAG } \\
\text { R:GCATGATCTATTGTGTTTACATTAGCGGGTAG }\end{array}$ & 89 \\
\hline
\end{tabular}

Function of candidate reference genes and GOIs as annotated in the SGD database $\mathrm{http}: / / \mathrm{db}$.yeastgenome.org. All ORF sequences were recovered from the SGD database. Forward (F) and reverse (R) primer sequences; PCR amplification efficiency (Eff). Genes highlighted in bold were selected from their apparent stability during growth on glucose (public microarray datasets from De Risi et al [26] and Gasch et al [27]). The remaining reference genes are commonly used internal controls in yeast studies. 


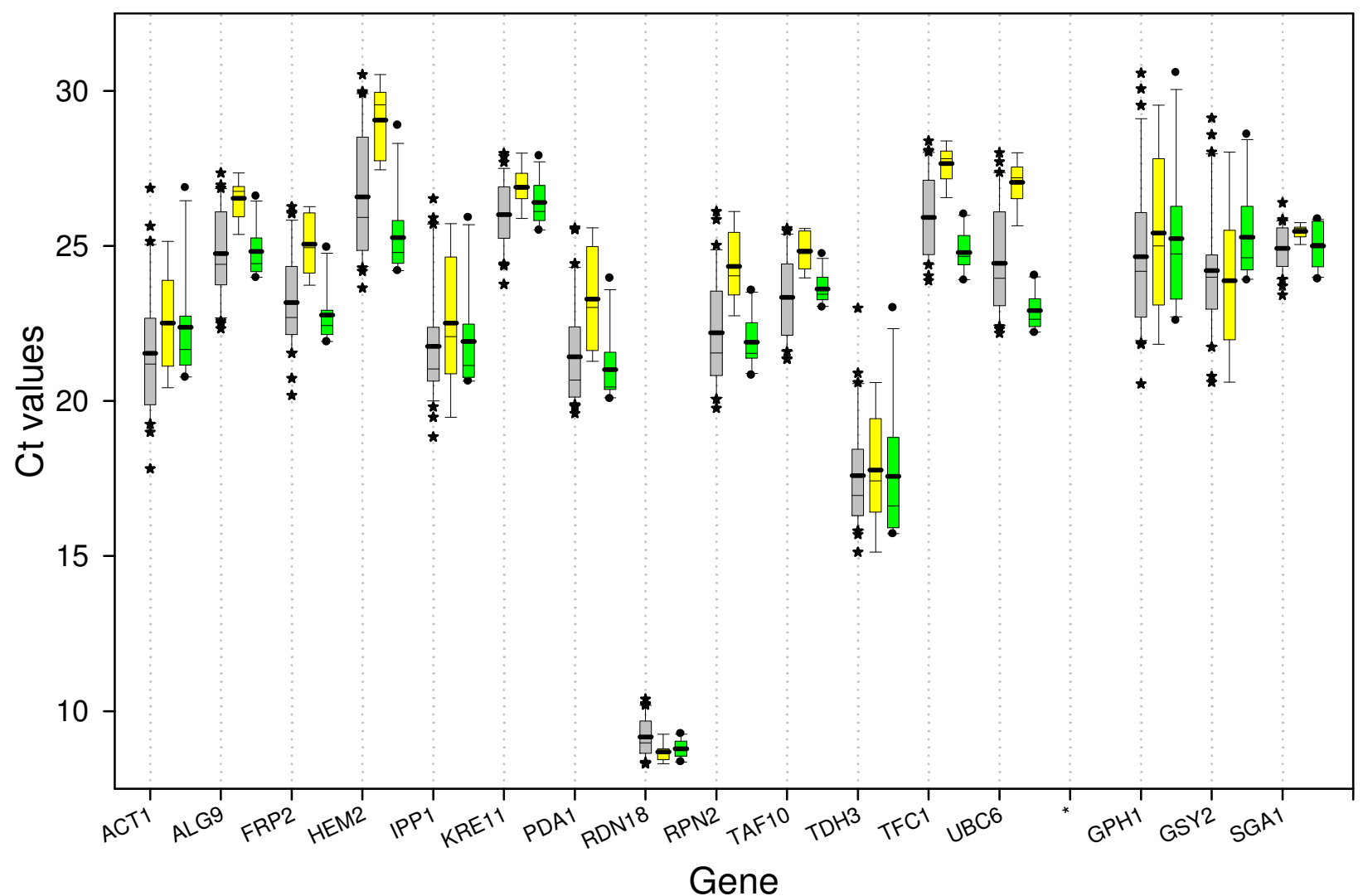

\section{Figure 3}

Distribution overview of expression levels $(\mathbf{C t})$ of the different genes. Boxplot representation of raw $\mathrm{Ct}$ values obtained from amplification curves. Lower and upper boundaries of the box indicate the 25 th and the 75 th percentile, respectively, the thin line within the box marks the median, and the whiskers (error bars) below and above the box indicate the I0th and 90 th percentiles. Mean (thick line) and outliers (*). Complete RNA sample set from the study ( $\mathrm{n}=32$, grey), sample set "A" ( $n=9$, yellow; see Figure 2, Glucose + Galactose) and sample set "K" ( $=11$, green; see Figure 2, WT + tps I $\Delta$ ). As stated in methods, the $25 \mu \mathrm{L}$ reaction mixes contained $5 \mu \mathrm{L}$ of cDNA preparation diluted 10 times, except for RDN/8 where cDNA was diluted 50 times. For a easy and preliminary estimation of the relative expression of a gene between two samples, a difference of $3.33 \mathrm{Ct}$ with $100 \%$ PCR efficiency represents 10 -fold over-expression or repression between two conditions $\left(\mathrm{N}_{2} / \mathrm{N}_{1}=\right.$ $\left.(I+E f f)^{\wedge}\left(C t_{1}-C t_{2}\right)\right)$; With PCR efficiency correction, the same $C t$ difference with only $90 \%$ efficiency signifies a 8.5 -fold variation of transcripts between the two samples.

a wide range of experimental conditions. Therefore, this set of genes, ALG9, TAF10, TFC1 and UBC6 should be preferentially used to calculate normalization factors in quantitative RT-PCR expression analysis in the yeast $S$. cerevisiae.

\section{Impact of reference gene selection on expression ratio values}

The strength of GeNorm to select the most suitable reference genes was demonstrated by comparing normalized data calculated from different subsets of potential HSKs. As is shown in Figure 5, the use of a normalization factor based on the geometric mean of expression levels of
UBC6, TAF10 and ALG9 $\left(\mathrm{NF}_{(\text {UBC6, TAF10, ALG9) }}\right)$ yielded expected expression patterns of the glycogen metabolic genes GSY2 and GPH1 during growth of the KT strain on glucose (see last results section for more details). Ratios of expression values were almost identical using the following 3 best genes based on geNorm classification $\mathrm{NF}_{(T F C 1}$, KRE11, FRP2), compare grey and hatched bars) or applying the normalization factor calculated from the six best genes together $\left(\mathrm{NF}_{(6 \text { best })}\right.$, not plotted). These results showed that, at least in this condition, any subset of three genes among the most stably expressed candidates was sufficient to calculate robust NF and to normalize expression of Genes of Interest (GOIs). 


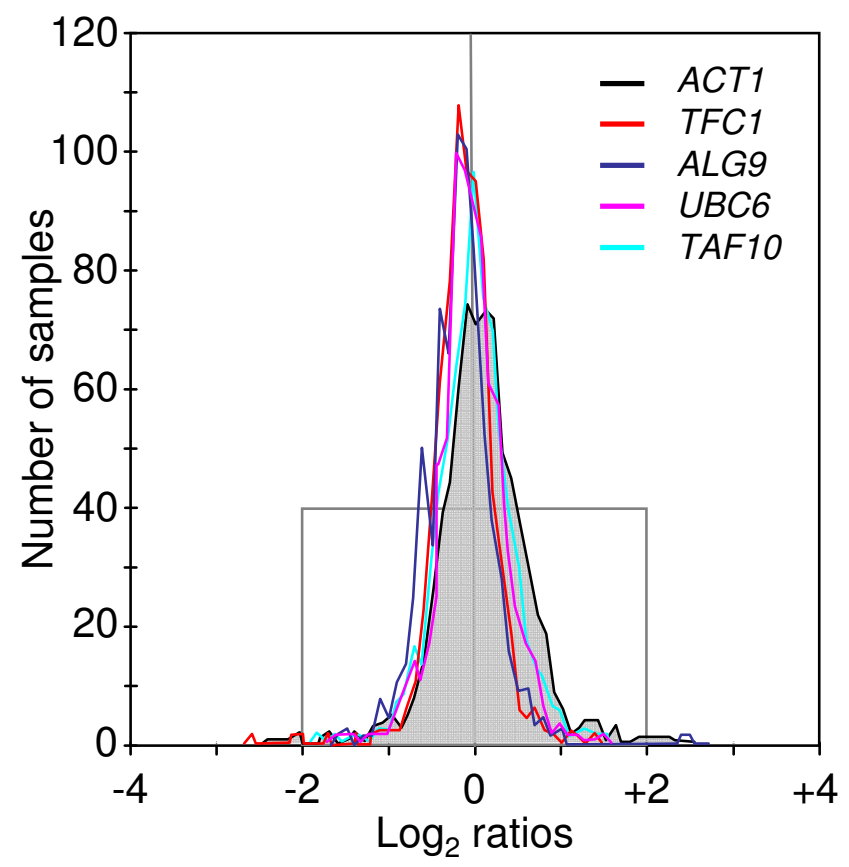

Figure 4

Expression summary as reported in the SGD Expression Connection tool. For each gene (depicted by different color lines), the pattern that is reported in this figure is a copy of the "expression summary" histogram that was obtained using the Expression Connection tool from the SGD server http://www.yeastgenome.org. This graph indicates the number of samples (also called 'experiments' on the SGD server), at a given expression ratio value, that could be found in all the microarray datasets stored on the SGD server (i.e. approx. 30 studies). The expression data reported on the axis are in log2 scale.

The advantage of using validated genes for normalization was further analyzed comparing expression results after normalization $\left(\mathrm{NF}_{(U B C G, T A F 10, A L G 9)}\right.$, etc) to those obtained by using non-validated reference genes, e.g. ACT1 $\left(\mathrm{NF}_{(A C T 1)}\right)$ or a combination of ACT1, PDA1 and IPP1 $\left(\mathrm{NF}_{(A C T 1, P D A 1, I P P 1)}\right)$. As it could be expected from the coregulation of these three genes during growth on glucose (Figure 5), identical expression data were obtained with $\mathrm{NF}_{(A C T 1)}$ and $\mathrm{NF}_{(A C T 1, P D A 1, I P P 1)}$ as normalization factors (compare empty and black dots for RDN18 and GOIs normalized expression data). In contrast, a strong discrepancy between normalization to ACT1 and normalization to validated genes was observed in biological samples collected in the post-diauxic phase (\#3 and \#4) and in the stationary phase (\#5). This strong deviation could be explained by the drop of ACT1 mRNA as well as that of transcripts of other HSK genes (IPP1 and PDA1) during these growth phases (Figure 5). To better visualize the advantage of using normalization to validated genes, data from sample set $\mathrm{B}$ were reported on a scatter plot (Figure 6), comparing data normalized to $\mathrm{NF}_{(T F C 1, K R E 11, F R P 2)}$ and $\mathrm{NF}_{(A C T 1)}$, respectively, to those normalized to $\mathrm{NF}_{(U B C 6}$, TAF10, ALG9) (Figure 6). A regression coefficient close to one $\left(\mathrm{R}^{2}=0.997\right)$ was calculated for $\mathrm{NF}_{(T F C 1, \text { KRE11, FRP2) }}$ versus $\mathrm{NF}_{(U B C G, T A F 10, A L G 9)}$. In contrast, the coefficient was extremely low for $\mathrm{NF}_{(A C T 1)}$ versus $\mathrm{NF}_{(U B C 6, T A F 10, A L G 9)}\left(\mathrm{R}^{2}=\right.$ $0.598)$, mainly due to expression data from PDS and SP samples.

Similar analyses were carried out by using different biological situations, as for instance, in a biological set combining samples from cultures on glucose and galactose to analyze the influence of the carbon source (Figure 7, set A), or from wild type and tps 1 mutants to analyze the impact of the mutation on the expression data (Figure 8, set K). Again, discrepancies in ratios of expression values calculated by normalization to the "best reference genes" and to ACT1, respectively, were evident in samples collected from yeast cultures entering the diauxic shift. The difference was even more pronounced with late stationary phase samples, as the difference could reach almost 10fold between the two procedures (see Figure 7 \&8). This discrepancy was visualized in the scatter plots presented in Figure 9, which report a larger range of ratio values than those in Figures 7 \&8. As expected, data from $\left(\mathrm{NF}_{\text {(TAF10, }}\right.$ $F R P 2, A L G 9))$ versus $\left(\mathrm{NF}_{(U B C 6, T F C 1, K R E 11)}\right)$ aligned with a good regression coefficient (panel $A, R^{2}=0.916$ ), while $\left.\mathrm{NF}_{(A C T 1}\right)$ did not correlate at all with $\mathrm{NF}($ UBCG, TFC1, KRE11) as shown by the worst regression coefficient of the study (panel $\mathrm{B}, \mathrm{R}^{2}=0.124$ ). Altogether, these results demonstrated the benefit of using multiple selected genes instead of a single, non-validated gene (e.g. ACT1) for accurate and reliable data normalization.

\section{Application to quantitative expression analysis of genes involved in glycogen metabolism}

To test the robustness of this subset of selected reference genes, we analyzed the transcriptional regulation of genes involved in glycogen metabolism in this yeast. It has been reported that large variations of reserve carbohydrate content are associated with coordinated transcriptional regulation of the cognate genes in response to changing growth conditions or under various genetic contexts $[23,24,28-33]$. When examining raw $\mathrm{Ct}$ values from GPH1 (glycogen phosphorylase) and GSY2 (glycogen synthase) in the complete dataset (Figure 3), the very long whiskers of the boxes and numerous outliers confirmed the high variability of the expression of these two genes. On the contrary, the SGA1 gene encoding the vacuolar amylo-1,4 $-1,6$ glucosidase [34] exhibited much lower dispersion of Ct values, indicating smaller expression change than GSY2 and GPH1 under our growth conditions. Using the 3 best reference genes for data normalization $\mathrm{NF}_{(U B C 6, T A F 10}$, $\left.{ }_{A L G 9)}\right)$, we confirmed the induction of GSY2 and GPH1 


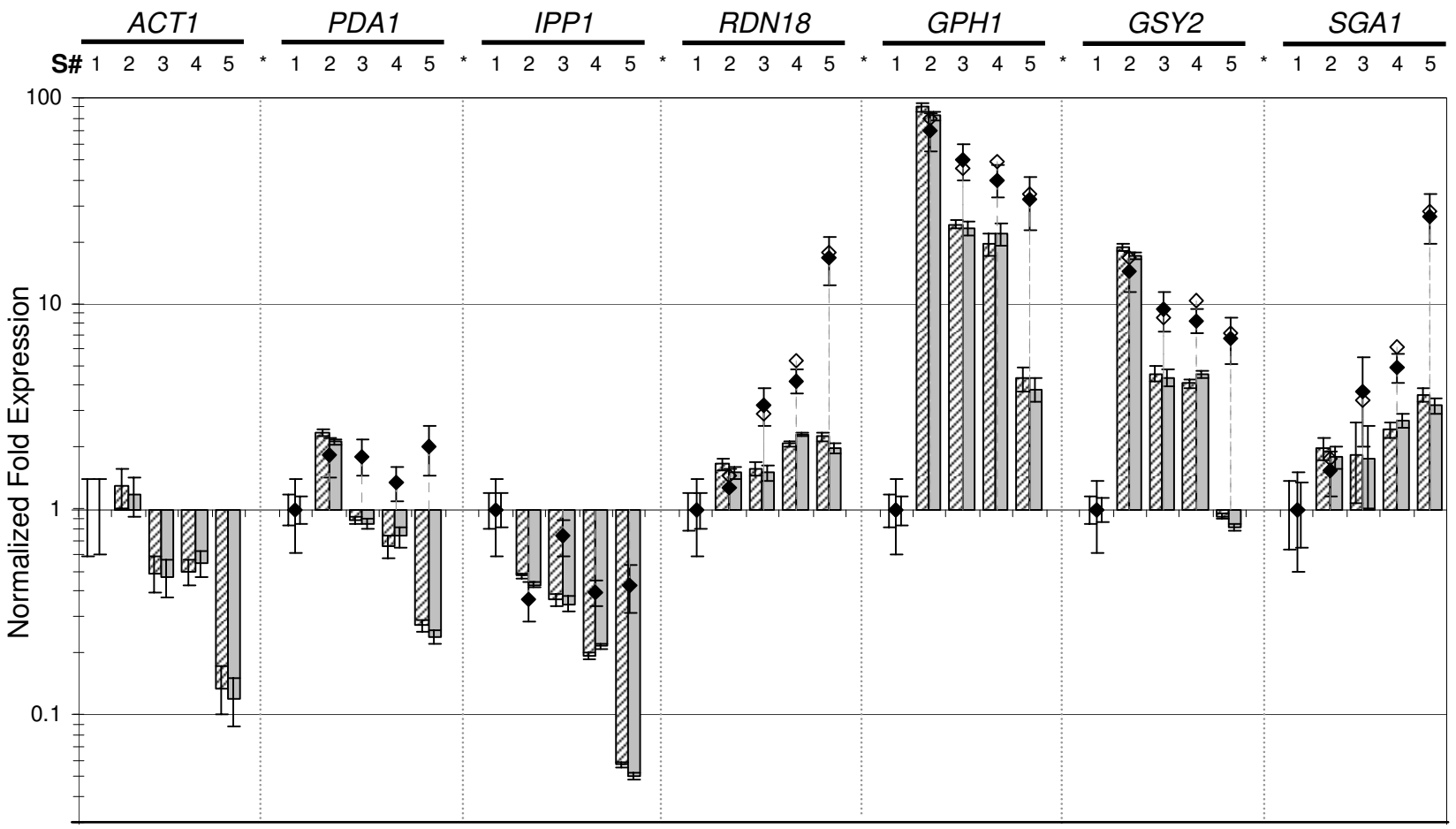

\section{Figure 5}

Effect of normalization strategies on expression ratios. Normalized expression of $A C T I, P D A I, I P P I, R D N / 8, G P H I$, GSY2 and SGAI, in 5 characteristic samples during growth on glucose (i.e. set "B" in Figure 2): early exponential phase (respirofermentative), entry in (disappearance of glucose) and exit from the diauxic shift, mid of post-diauxic (respiratory) growth, and 3 days stationary phase. The exponential phase sample (S\#I) was used as calibrator. Normalization was performed using the three most stable genes $\left(\mathrm{NF}_{(U B C 6, T A F I O, A L G 9)}\right.$, dashed bar), the following 3 best $\left(\mathrm{NF}_{(T F C I, K R E I I, F R P 2)}\right.$, grey bar), ACTI alone $\left(\mathrm{NF}_{(A C T I)}\right.$, black diamond) or using ACTI, PDAI and IPPI (NF$(A C T I, P D A I, I P P I)$, empty diamond). Normalized expression data and error bars were calculated using the gene expression module of the BIORAD iQ5 software, which follows models and error propagation rules outlined in the geNorm manual. For the sake of clarity, we did not plot standard deviation of ratios obtained from $\mathrm{NF}_{(A C T I, \text { PDAI, IPPI). }}$.

between the exponential phase ( $\$$ \#1, calibrator sample) and the entry into the diauxic shift (S\#2), and found remarkable expression ratios close to 20 for GSY2 and almost 100 for GPH1 (Figure 5). Moreover, this normalization procedure allowed us to show that the expression of these two genes dropped immediately after the diauxic shift, to return to the initial level in stationary phase for GSY2, or close to it for GPH1, while ACT1 normalization indicated stable and high expression of these two genes all along these growth phases. In contrast to GSY2 and GPH1, the expression of $S G A 1$ showed a modest increase when cells entered the diauxic shift to reach a 3-fold activation in the stationary phase. We also analyzed for the first time transcriptional patterns in galactose-grown cells (Figure 7). Unexpectedly, the expression of GPH1 and GSY2 was already very high in the exponential phase (S\#6) as compared to cultures on glucose (S\#1), and it did not further increase as cells entered the diauxic shift on this carbon source, whereas glycogen accumulated with a kinetic almost similar to that on glucose (see additional files 1 \&2). The expression of these two genes then dropped during the post diauxic phase to reach levels even lower than on glucose in the stationary phase. In contrast to GPH1 and GSY2, SGA1 expression was not affected by the carbon source. Finally, expression patterns of these three genes on galactose were the same in the CEN.PK genetic background (Figure 8) as in the KT strain (Figure 7).

The loss of TPS1 function had a strong impact on the glycogen accumulation pattern on galactose, as it caused hyper-accumulation of the polymer at the end of the exponential phase, and also promoted its rapid and sustained degradation during post-diauxic and stationary phases (Figure 1, and in additional file 2). Therefore, to get a preliminary idea on how this mutation could alter the glycogen kinetics at the transcriptional level, we quan- 


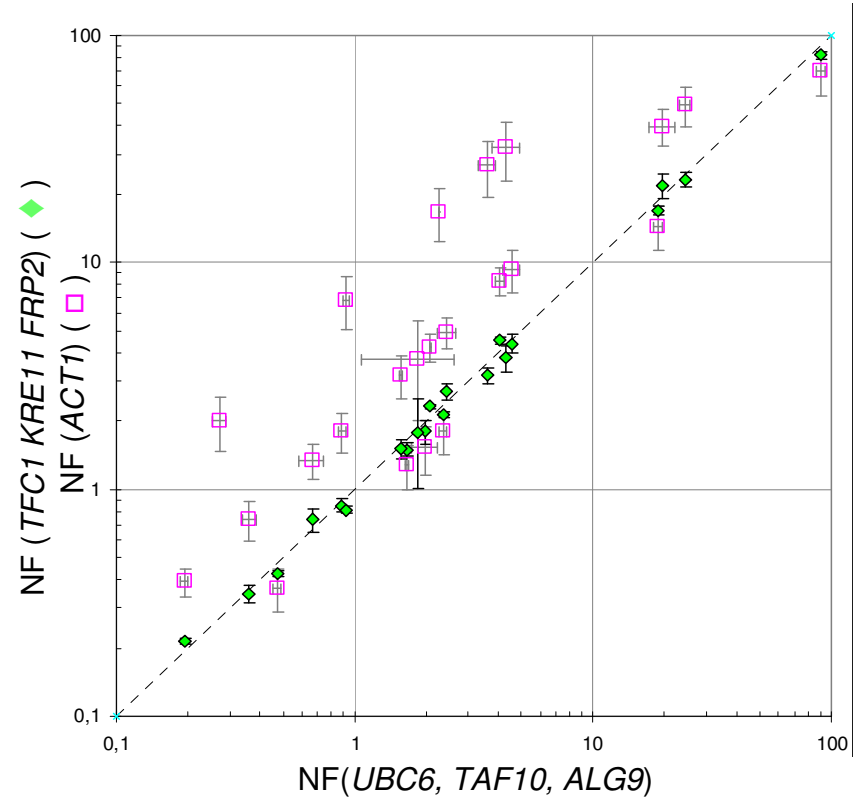

Figure 6

Degree of correlation between normalization strategies in simple datasets. Scatter plot of the data illustrated in Figure 5. $X$ axis: ratios calculated using the three most stable genes $\left(\mathrm{NF}_{(\mathrm{UBC6}, \mathrm{TAFIO}, A L G 9)}\right)$; $\mathrm{Y}$ axis: ratios calculated using $\mathrm{NF}_{(T F C I, K R E I I, F R P 2)}$ (green diamond) or $\mathrm{NF}_{(A C T I)}$ (purple square). Horizontal and vertical error bars: Standard deviation on $X$ and $Y$ ratio, respectively. Grey Dotted line: $y=x$. The equation and correlation coefficient of the linear regression fit (not reported) are $y=0,9178 x, R^{2}=0,997$ (green diamonds), and $y=0,9327 x, R^{2}=0,598$ (purple squares).

tified the expression of GSY2, GPH1 and SGA1 during growth on galactose of the WT and its tps 1 derivative strain. It is shown in Figure 8 that the expression pattern of GPH1 or GSY2 was identical in both the wild type and in the mutant strains. The only noticeable difference was for SGA1 gene whose expression was already increased in the exponential phase in a tps1 mutant ( $\mathrm{S \# 14)}$ as compared to the wild type strain (S\#10, calibrator).

\section{Discussion}

In the yeast Saccharomyces cerevisiae, the microarray datasets available on the Saccharomyces Genome Database website now represent a vast treasure-trove of reference genes suitable for gene expression normalization. We therefore used the Gene Expression Connection tool [35] to search for a set of stably expressed genes in growth dynamics [26,27]. Other approaches have recently been proposed for selection of internal controls, with statistical analysis of large microarray datasets [36,37]. Nevertheless, as stated by the authors [36,37], these in silico searches for stable internal controls must be accompanied by lab-bench work to verify that selected candidate genes are reliable for normalization in a specific experimental context. This is what we actually performed in the present work. Out of 13 genes analyzed in this study, i.e. 8 functionally unrelated genes selected from the microarray datasets together with 5 standard reference genes (e.g. ACT1, PDA1 etc), we identified ALG9, TAF10, TFC1, UBC6 and to a lesser extent KRE11, as the most stable genes in our experimental conditions. Another very important result from this study was the observation that geometric averaging of any subset of three genes among the six most stable genes led to very similar normalization factors, therefore highlighting the robustness of our gene selection. This conclusion was further supported by the weak expression change of this subset of genes as revealed by a survey of microarray datasets from the SGD server, i.e. in approximately 30 large scale transcriptomic studies, which altogether correspond to several hundreds of different samples. Therefore, ALG9, TAF10, TFC1 and UBC6 genes are the most pertinent reference genes, not only for growth phase related mRNA profiling in $S$. cerevisiae, but more generally for quantitative gene expression analysis with samples that cover a large panel of physiological and metabolic states.

Probably because of the tedious experimental validation of a suitable set of reference genes, the common practice by many authors was to use ACT1, PDA1, TDH3 or RDN18 as a single reference gene for normalization in $S$. cerevisiae expression studies, assuming a steady state level of expression for these so-called housekeeping genes. However, the validity of ACT1 as an internal standard has been already questioned [38] and PDA1 was preferred to ACT1 for normalization in Northern blot analysis since stationary phase samples showed a more significant drop of ACT1 mRNA. Still, by the use of Northern blot analysis, it was indeed demonstrated that ACT1 is a representative gene whose transcription is typically repressed following the shift from logarithmic growth to stationary phase $[39,40]$. As preliminary molecular clues on how down regulation of this gene occurs, these authors showed that topoisomerase I has a regulatory role in the transcriptional repression of most of the genes following the diauxic shift and in the stationary phase [39]. The second work reported a major role of the RNA polymerase II subunit RPB4, which permitted appropriate transcriptional responses during stress, including nutrient stress that accompanies entry into stationary phase [40]. Global transcriptome analysis [27] also showed that ACT1 mRNA levels did decrease significantly during growth in a glucose rich medium, a pattern that was confirmed by using absolute quantification by real time RT-PCR [41]. In our study, using the geometric averaging of multiple selected reference genes for relative quantification, we also found a significant drop of ACT1 transcripts and of other frequently used genes like PDA1 (E1 alpha subunit of the 


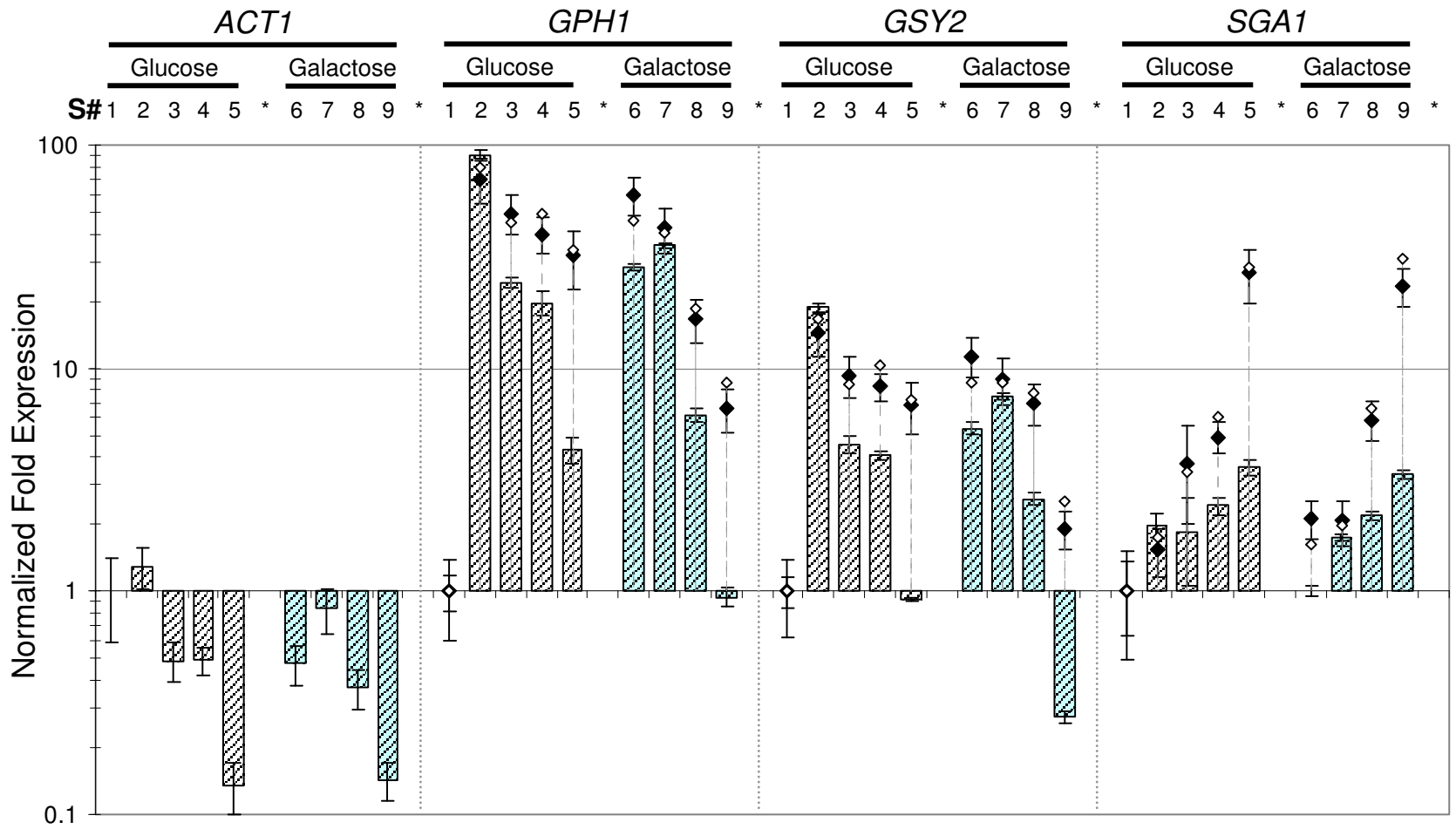

\section{Figure 7}

Effect of carbon source on expression profiles of the commonly-used ACTI and genes of interest. Normalized expression of $A C T I$ and GPHI, GSY2, SGAI in sample set "A" $(n=9)$. This set includes 5 samples selected during growth on glucose (grey, see legend from Figure 5) and 4 characteristic samples from growth on galactose (blue): early exponential phase (respiro-fermentative), entry in the diauxic shift (disappearance of galactose), mid of post-diauxic (respiratory) growth, and 3 days stationary phase. The exponential phase sample on glucose was used as calibrator for this sample set. Normalization was

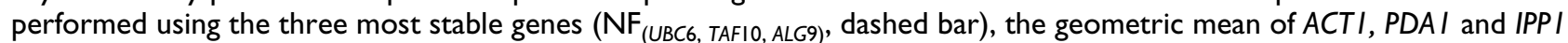
$\left(\mathrm{NF}_{(A C T I, P D A I, I P P I)}\right.$, empty diamond) or ACTI alone $\left(\mathrm{NF}_{(A C T I)}\right.$, black diamond). Normalized expression data and error bars calculated as described in Figure 5 . For the sake of clarity, we did not plot standard deviation of ratios obtained from NF (ACTI, PDAI, IPPI).

pyruvate dehydrogenase complex) and IPP1 (cytoplasmic inorganic pyrophosphatase) when cells proceed from the exponential phase of growth to the stationary phase. Therefore, as already mentioned by Monje-Cajas et al [41], the use of ACT1 and related transcripts would seriously over-estimate (approx. 10-fold) expression levels of genes of interest in stationary phase, leading to erroneous conclusions. Moreover, the genes encoding glycolytic enzymes, for example TDH3 (glyceraldehyde-3-phosphate dehydrogenase), were amongst the first yeast genes to be isolated. Because of their high expression levels, their promoters have been widely used to construct yeast expression vectors [42-47] and as model systems to study transcription [48]. Nevertheless, as details of the organisation of glycolytic promoters have emerged, it has become clear that these "simple HouseKeeping genes" actually have sophisticated molecular mechanisms controlling their expression [48]. As reviewed in this latter reference, some glycolytic enzymes were induced by glucose while others such as ENO1 and TDH3 appeared to be constitutively expressed irrespective of the carbon source (glucose or other sugars versus non-fermentable carbon sources). Our results, i.e. the large dispersion of $\mathrm{Ct}$ values from $\mathrm{TDH} 3$ in our experimental conditions (Figure 3 ) and the fact that this gene ranked amongst the worst candidate reference genes (Additional File 3), somehow contradicted this conclusion and do not encourage the use of TDH3 as a constitutive, internal reference gene for reliable gene normalization. Finally, the gene RDN18 encoding the 18 srRNA could have been accepted for normalization, but the very strong expression that is several orders of magnitude above the mean expression of tested reference genes and GOIs, together with the fact that RDN18 does not encode mRNA precluded its use as an internal reference gene. 


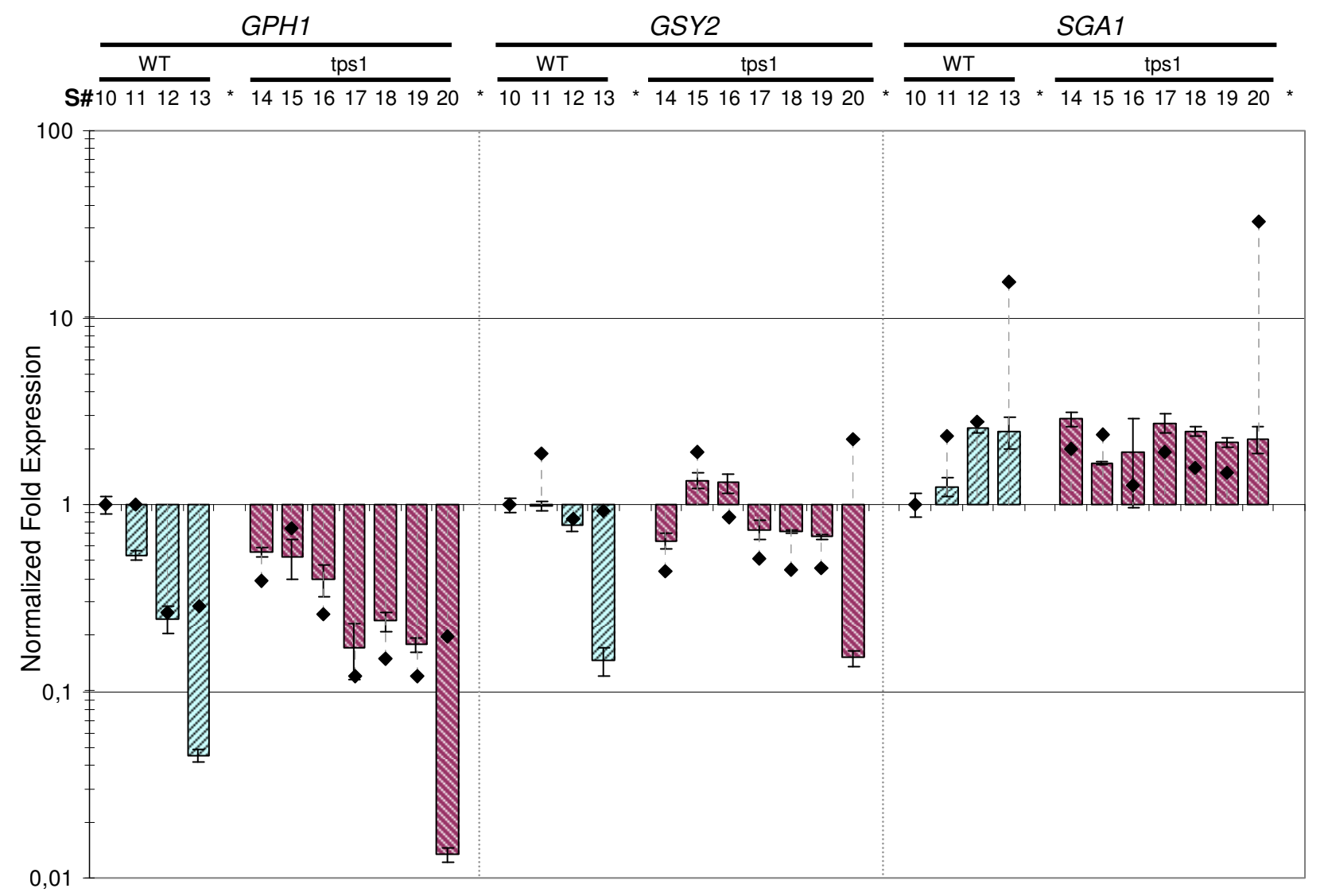

Figure 8

Effect of tps I mutation on expression profiles of genes of interest. Normalized expression of GPHI, GSY2 and SGA I in WT and tps I $\Delta$ strains grown on galactose (set "K"). This set includes i/4 samples selected during growth of the WT strain (blue): early exponential phase [respiro-fermentative], exit from the diauxic shift, mid of post-diauxic [respiratory] growth, and after 3 days in stationary phase; and ii/7 samples from growth of the tps / $\Delta$ strain (red): early exponential phase [respiro-fermentative], entry in and exit from the diauxic shift, early and mid respiratory growth (i.e. just before and just after glycogen peak), entry in and after 3 days in stationary phase. The exponential phase sample of the WT strain was used as calibrator. Normalization was performed using the three most stable genes in this sample set $\left(\mathrm{NF}_{(U B C 6, T F C I, K R E I I)}\right.$, dashed bar) or ACTI alone $\left(\mathrm{NF}_{(A C T I)}\right.$, black diamond). Normalized expression data and error bars calculated as described in Figure 5 . For the sake of clarity, we did not plot standard deviation of ratios obtained using ACTI as reference.

As an application of this normalization procedure with carefully selected reference genes, we reinvestigated in a quantitative manner the transcriptional response of genes implicated in glycogen metabolism, since this physiological event is an interesting hallmark during long term yeast cultures with significant transcriptional remodeling and huge variations of the polysaccharide content $[23,24]$. This study confirmed known transcriptional induction patterns of genes encoding glycogen phosphorylase (GPH1) and glycogen synthase (GSY2) that paralleled the accumulation of glycogen between the exponential phase and the diauxic shift on glucose $[23,24]$, with a notable induction ratio of approx. 100-fold for GPH1 and 20-fold for GSY2. For the first time, this study also provided expression data of these genes on galactose. Despite similar growth pattern and glycogen accumulation kinetic as compared to glucose, the growth on galactose radically changed the expression pattern of these two genes. Transcripts levels were already very high in the exponential phase as compared to glucose, and we could not observe any upregulation at the entry into the diauxic-shift. Therefore, the glycogen accumulation that was observed at the end of the exponential phase during growth on galactose probably came from a concomitant activation of Gsy2p and the inactivation of Gph1p by protein phosphatases mediated dephosphorylation events [23]. With respect to the vacuolar amylo-glucosidase (SGA1), the large-scale transcriptional study from Gash and co-workers showed 


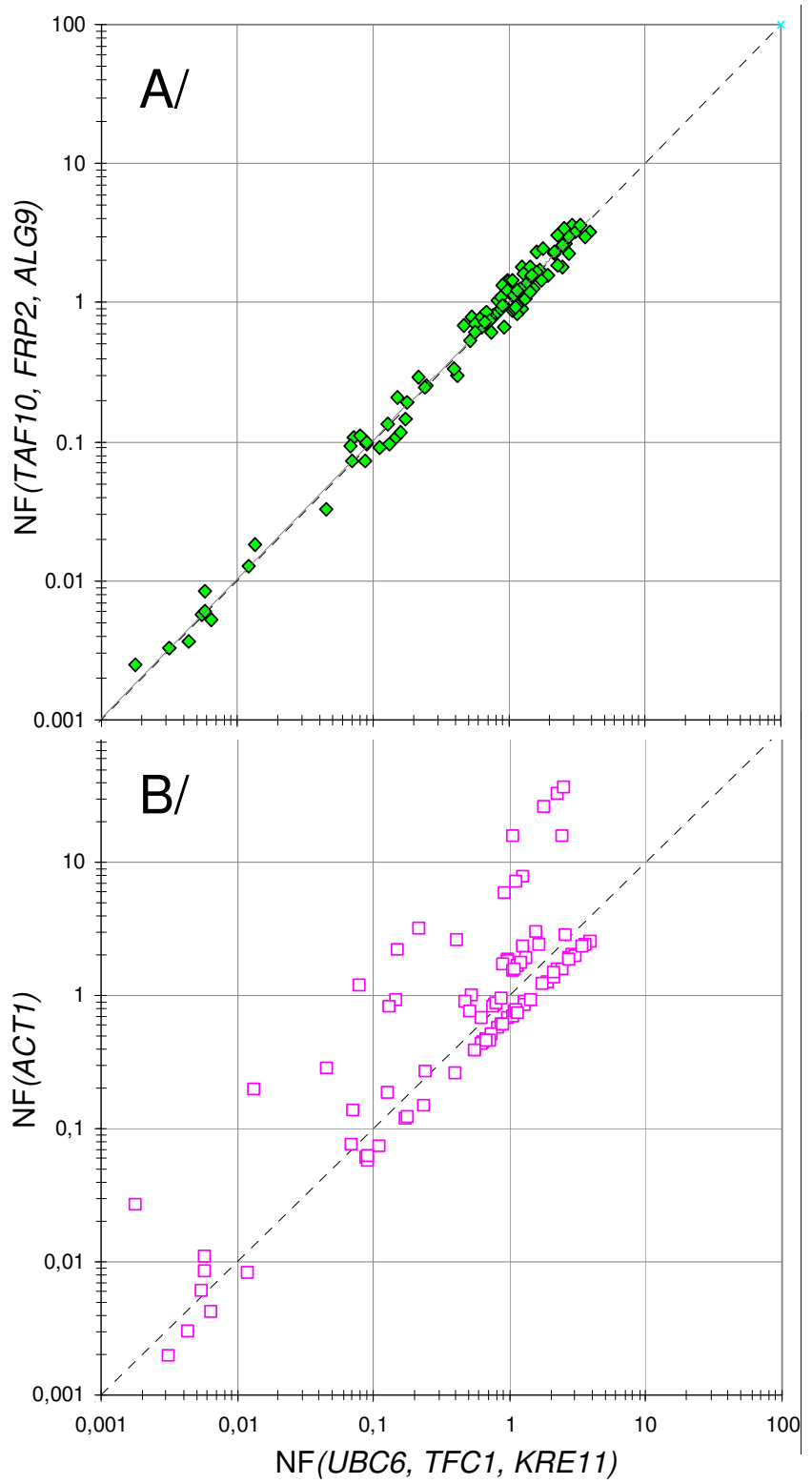

Figure 9

Degree of correlation between normalization strategies in more heterogeneous datasets. Scatter plot of ratio values obtained from sample set "K" for genes which together illustrated a wide range of responses (from strong over-expression to repression, see Figure 8 for some of them). $X$ axis: ratios calculated using the three most stable genes $\left(\mathrm{NF}_{(U B C 6, T F C I, K R E I I)}\right) ; \mathrm{Y}$ axis: ratios calculated using $\mathrm{NF}_{(T A F I O, F R P 2, A L G 9)}(\mathrm{A})$ and $\mathrm{NF}_{(A C T I)}(\mathrm{B})$. Dotted line: $\mathrm{y}=\mathrm{x}$. The equation and correlation coefficient of the linear regression fit (not reported) were $y=1.030 x, R^{2}=0.916(A)$ and $y=$ $2.405 x, R^{2}=0.124(B)$. some transcriptional activation of this gene during long term yeast cultures on glucose $[27,49]$. Wang and coworkers [49] also provided indirect evidence of transcriptional activation of SGA1 in stationary phase, showing a significant role of SGA1 gene deletion on glycogen accumulation pattern in this phase of growth. Their result suggested that SGA1 may not be strictly sporulation specific, but could be activated under starvation, like in the late stationary phase. Our study supported this assertion and showed that the expression of SGA1 increased during the post-diauxic growth, with maximal 3-fold activation in stationary phase in wild type strains. On the other hand, the causal relationship between higher expression of $S G A 1$ and faster glycogen degradation in tps1 derivative strains as compared to the WT remains to be investigated.

\section{Conclusion}

A set of putative internal control genes for real-time RTPCR analysis was selected from public microarray datasets. Using geNorm software, we validated that ALG9, TAF10, TFC1, UBC6 and to a lesser extent KRE11, turned out to be the most stable genes under all conditions investigated. Geometric averaging of their expression data was then applied to smooth individual variation and to calculate robust normalization factors, which allowed for the demonstration that the use of a single reference gene like ACT1 could lead to erroneous expression data. This set of reference genes was carefully tested in a context of large heterogeneity of samples (different physiological states during long term S. cerevisiae cultures, different carbon sources and genetic contexts) and applied to explore quantitatively the transcriptional regulation of genes involved in glycogen metabolism in this yeast. This study brought new insights into the transcriptional control of GSY2, GPH1 and SGA1 during long term growth on glucose and galactose, suggesting a potential role of SGA1 in the management of glycogen storage in tps 1 cells. To summarize, this work provides a set of pertinent reference genes that should be used for validation of expression data from microarrays experiments and more generally for reliable real time RT- PCR analysis in yeast.

\section{Methods \\ Yeast strains, growth conditions and sampling}

The Saccharomyces cerevisiae strains, CEN.PK113-7D [50] and its tps1 derivative [51], and JLP48-3B (KT1112 context [24]), were grown at $30^{\circ} \mathrm{C}$ in a synthetic minimal medium containing $0.17 \%(\mathrm{w} / \mathrm{v})$ yeast nitrogen base (DIFCO), $0.5 \%(\mathrm{w} / \mathrm{v})$ ammonium sulfate and $2 \%(\mathrm{w} / \mathrm{v})$ galactose (YNGal) or glucose (YNGlu). The use of prototroph strains did avoid amino acid complementation of the medium. The $\mathrm{pH}$ was adjusted to 5.0 with succinic acid and sodium hydroxide. Cell growth was followed by measurement of OD (600 nm) during at least 10 days. For real independency of duplicates, shake-flasks cultures 
were performed neither simultaneously, nor from the same inoculums. The residual extracellular carbon source was quantified by HPLC. Intracellular glycogen and trehalose were measured as described in [52]. Yeast samples for real-time PCR analysis (approx. $10^{8}$ cells) were centrifuged (3,000 $\left.\mathrm{rpm}, 4^{\circ} \mathrm{C}, 3 \mathrm{~min}\right)$, and the cell pellets were immediately frozen in liquid nitrogen and stored at $-80^{\circ} \mathrm{C}$ until RNA extraction.

\section{Total RNA extraction}

Frozen cells were mechanically disrupted using a ball mill (Mikro-Dismembrator S; B. Braun Biotech International). Total RNA was extracted using the RNeasy mini kit (Qiagen). To eliminate genomic DNA contamination, an additional DNase treatment was performed according to the RNeasy kit instruction with the RNase-free DNase set (Qiagen). The extracted RNA was quantified using the Bioanalyzer 2100 with the RNA 6000 Nano LabChip kit (Agilent) and the ND-1000 UV-visible light spectrophotometer (NanoDrop Technologies). As another preliminary quality control assay, the absence of contaminant genomic DNA in RNA preparations was verified using RNA as a template in real-time PCR assays (minus RT control, i.e. RNA not reverse-transcribed to cDNA).

\section{Quantitative RT-PCR}

Oligonucleotides for real-time PCR (Table 1) were designed using Beacon Designer 2.0 software (PREMIER Biosoft International), which included a BLAST analysis against $S$. cerevisiae Genome sequence for specificity confidence, and analysis using the Mfold server to avoid positioning on risky secondary structures.

One microgram of total RNA was reverse-transcribed into cDNA in a $20 \mu \mathrm{L}$ reaction mixture using the iScript cDNA synthesis kit (Bio-Rad). The cDNA levels were then analyzed using the MyIQ real-time PCR system from Bio-Rad. Each sample was tested in duplicate in a 96-well plate (Bio-Rad, CA). The reaction mix (25 $\mu \mathrm{L}$ final volume) consisted of $12.5 \mu \mathrm{L}$ of iQ SYBR Green Supermix (Bio$\mathrm{Rad}), 2.5 \mu \mathrm{L}$ of each primer (250 $\mathrm{nM}$ final concentration), $2.5 \mu \mathrm{L}$ of $\mathrm{H}_{2} \mathrm{O}$, and $5 \mu \mathrm{L}$ of a $1 / 10$ dilution of the cDNA preparation. The absence of genomic DNA in RNA samples was checked by real-time PCR before cDNA synthesis (minus RT control). A blank (No Template Control) was also incorporated in each assay. The thermocycling program consisted of one hold at $95^{\circ} \mathrm{C}$ for $4 \mathrm{~min}$, followed by 40 cycles of $10 \mathrm{~s}$ at $95^{\circ} \mathrm{C}$ and $45 \mathrm{~s}$ at $56^{\circ} \mathrm{C}$. After completion of these cycles, melting-curve data were then collected to verify PCR specificity, contamination and the absence of primer dimers.

The PCR efficiency of each primer pair (Eff) was evaluated by the dilution series method using a mix of sample cDNAs as the template. Briefly, it was determined from standard curves using the formula 10(-1/slope). For the calculations, the base of the exponential amplification function was used (e.g. 1.94 means 94\% amplification efficiency). Relative expression levels were determined with efficiency correction [53], which considers differences in primer pair amplification efficiencies between target and reference genes, and results in a more reliable estimation of the "real expression ratio" than the $2 \Delta \Delta \mathrm{Ct}$ method [9]. Expression data and associated technical errors on duplicates were calculated using the gene expression module of the BIORAD iQ5 software, which follows models and error propagation rules outlined in the geNorm manual.

\section{Data analysis using geNorm}

The stability of mRNA expression of tested reference genes was evaluated by using the geNorm VBA applet for Microsoft Excel [14]. This program calculates the gene expression stability measure " $\mathrm{M}$ " for a potential reference gene as the average pair-wise variation for that gene with all other tested genes. Then it ranks genes considering that those with the lowest $M$ value have the most stable expression. Finally, it determines the optimal number of genes for an accurate normalization by calculating the pair-wise variation $\left(\mathrm{V}_{(n / n+1)}\right)$ between two normalization factors, namely $\mathrm{NF}_{n}$ (normalization factor based on the geometric mean of the $n$ most stable genes) and $\mathrm{NF}_{\mathrm{n}+1}$ : if $\mathrm{V}_{\mathrm{n} / \mathrm{n}+1}$ is superior to 0.15 as a cut-off value, one could consider that the $(n+1)^{\text {th }}$ gene has a significant effect on normalization quality and should preferably be included for calculation of a reliable normalization factor. Authors of geNorm nevertheless recommend the minimal use of the three most stable internal control genes for calculation of the normalization factor $\left(\mathrm{NF}_{3}\right)$, and stepwise inclusion of more control genes until the $(n+1)^{\text {th }}$ gene has no significant contribution to the newly calculated normalization factor.

\section{Authors' contributions}

JLP, MAT and JMF conceived the study. MAT carried out SGD microarray datasets analysis, primer design and their validation; MAT and MD carried out the cultures, samples treatment and qPCR analysis. JLP and JMF wrote the manuscript and all authors read and approved the final version. 


\section{Additional material}

\section{Additional file 1}

Growth curve and glycogen content of WT strain on glucose and galactose. Growth (cells) and glycogen content during cultures of KT strain on glucose (set B from Figure 2) and galactose (set C from Figure 2). Cell samples (red dots) analyzed by real-time RT-PCR and sample numbering ( $S \#$ followed by red numbers in the blue area). Cells $\left(\mathrm{OD}_{600}\right)$, Glycogen ( $\mu$ g eq.glucose/OD unit).

Click here for file

[http://www.biomedcentral.com/content/supplementary/14712199-10-99-S1.pdf]

\section{Additional file 2}

Growth curve and glycogen content of WT and tps1 strains. Growth (cells) and glycogen content during cultures of CEN.PK strains on galactose, WT (set D from Figure 2) and tps1 (set $H$ from Figure 2). Legend as in Additional file 1.

Click here for file

[http://www.biomedcentral.com/content/supplementary/14712199-10-99-S2.pdf]

\section{Additional file 3}

Ranking of reference genes according to their expression stability. Compiled data from all sample sets. For each set (A to M), genes are ranked from the least stable (left) to the most stable (right). The two most stable genes cannot be ranked in order. Gene expression stability value (Upper panel) as a function of gene name (lower panel).

Click here for file

[http://www.biomedcentral.com/content/supplementary/14712199-10-99-S3.pdf]

\section{Acknowledgements}

This work was partially supported by ANR Blanc $n^{\circ} 05-2-42$ I 28 and by Genopole grant (2005-2007) to JMF. We are indebted to Dr. S. Sokol for his help with statistical analysis, Dr. Thomas Walther for critical reading, and Christine Rettew (Drexel University) for copyediting the manuscript.

\section{References}

I. Bustin SA, Benes V, Nolan T, Pfaffl MW: Quantitative real-time RT-PCR--a perspective. J Mol Endocrinol 2005, 34(3):597-60I.

2. Kubista M, Andrade JM, Bengtsson M, Forootan A, Jonak J, Lind K, Sindelka R, Sjoback R, Sjogreen B, Strombom L, et al:: The real-time polymerase chain reaction. Mol Aspects Med 2006, 27(23):95-125.

3. VanGuilder HD, Vrana KE, Freeman WM: Twenty-five years of quantitative PCR for gene expression analysis. Biotechniques 2008, 44(5):619-626.

4. Wong ML, Medrano JF: Real-time PCR for mRNA quantitation. Biotechniques 2005, 39(1):75-85.

5. Nolan T, Hands RE, Bustin SA: Quantification of mRNA using real-time RT-PCR. Nat Protoc 2006, I(3): I559-I 582.

6. Ho-Pun-Cheung A, Cellier D, Lopez-Crapez E: [Considerations for normalisation of RT-qPCR in oncology]. Ann Biol Clin (Paris) 2008, 66(2):121-129.

7. Huggett J, Dheda K, Bustin S, Zumla A: Real-time RT-PCR normalisation; strategies and considerations. Genes Immun 2005, 6(4):279-284

8. Liu ZL, Slininger PJ: Universal external RNA controls for microbial gene expression analysis using microarray and qRTPCR. J Microbiol Methods 2007, 68(3):486-496.

9. Livak KJ, Schmittgen TD: Analysis of relative gene expression data using real-time quantitative PCR and the 2(-Delta Delta C(T)) Method. Methods 200I, 25(4):402-408.
10. Cikos S, Bukovska A, Koppel ]: Relative quantification of mRNA: comparison of methods currently used for real-time PCR data analysis. BMC Mol Biol 2007, 8: 1 I 3.

II. Pfaffl MW: Quantification strategies in real-time PCR. In A-Z of quantitative PCR Volume 5. Edited by: Bustin S. La jolla, CA, USA: International University Line (IUL); 2003:912.

12. Rebrikov DV, Trofimov D: [Real-time PCR: approaches to data analysis (a review)]. Prikl Biokhim Mikrobiol 2006, 42(5):520-528.

13. Andersen CL, Jensen JL, Orntoft TF: Normalization of real-time quantitative reverse transcription-PCR data: a model-based variance estimation approach to identify genes suited for normalization, applied to bladder and colon cancer data sets. Cancer Res 2004, 64(I 5):5245-5250.

14. Vandesompele J, De Preter K, Pattyn F, Poppe B, Van Roy N, De Paepe A, Speleman F: Accurate normalization of real-time quantitative RT-PCR data by geometric averaging of multiple internal control genes. Genome Biol 2002, 3(7):RESEARCH0034.

15. Pfaffl MW, Tichopad A, Prgomet C, Neuvians TP: Determination of stable housekeeping genes, differentially regulated target genes and sample integrity: BestKeeper--Excel-based tool using pair-wise correlations. Biotechnol Lett 2004, 26(6):509-5 I5.

16. Dallas PB, Gottardo NG, Firth MJ, Beesley AH, Hoffmann K, Terry PA, Freitas JR, Boag JM, Cummings AJ, Kees UR: Gene expression levels assessed by oligonucleotide microarray analysis and quantitative real-time RT-PCR -- how well do they correlate? BMC Genomics 2005, 6(I):59.

17. Provenzano M, Mocellin S: Complementary techniques: validation of gene expression data by quantitative real time PCR. Adv Exp Med Biol 2007, 593:66-73.

18. Stahlberg A, Elbing K, Andrade-Garda JM, Sjogreen B, Forootan A, Kubista M: Multiway real-time PCR gene expression profiling in yeast Saccharomyces cerevisiae reveals altered transcriptional response of $A D H$-genes to glucose stimuli. BMC Genomics 2008, 9:170

19. Vaudano E, Costantini A, Cersosimo M, Del Prete V, Garcia-Moruno E: Application of real-time RT-PCR to study gene expression in active dry yeast (ADY) during the rehydration phase. Int Food Microbiol 2009, I 29(I):30-36.

20. Nailis H, Coenye T, Van Nieuwerburgh F, Deforce D, Nelis HJ: Development and evaluation of different normalization strategies for gene expression studies in Candida albicans biofilms by real-time PCR. BMC Mol Biol 2006, 7:25.

21. Fang W, Bidochka MJ: Expression of genes involved in germination, conidiogenesis and pathogenesis in Metarhizium anisopliae using quantitative real-time RT-PCR. Mycol Res 2006, I I0(Pt I0): I|65-II7|

22. Bohle K, Jungebloud A, Gocke Y, Dalpiaz A, Cordes C, Horn H, Hempel DC: Selection of reference genes for normalisation of specific gene quantification data of Aspergillus niger. J Biotechnol 2007, I32(4):353-358.

23. Francois J, Parrou JL: Reserve carbohydrates metabolism in the yeast Saccharomyces cerevisiae. FEMS Microbiol Rev 200I, 25(I): 125- I 45

24. Parrou JL, Enjalbert B, Plourde L, Bauche A, Gonzalez B, Francois J: Dynamic responses of reserve carbohydrate metabolism under carbon and nitrogen limitations in Saccharomyces cerevisiae. Yeast 1999, 15(3):19|-203.

25. Gancedo C. Flores CL: The importance of a functional trehalose biosynthetic pathway for the life of yeasts and fungi. FEMS Yeast Res 2004, 4(4-5):35I-359.

26. De Risi JL, lyer VR, Brown PO: Exploring the metabolic and genetic control of gene expression on a genomic scale. Science 1997, 278(5338):680.

27. Gasch AP, Spellman PT, Kao CM, Carmel-Harel O, Eisen MB, Storz $G$, Botstein D, Brown PO: Genomic expression programs in the response of yeast cells to environmental changes. Mol Biol Cell 2000, I I ( I 2):424I I-4257.

28. Hwang PK, Tugendreich S, Fletterick RJ: Molecular analysis of GPHI, the gene encoding glycogen phosphorylase in Saccharomyces cerevisiae. Mol Cell Biol I989, 9(4):1659-1666.

29. $\mathrm{Ni} \mathrm{HT}$, LaPorte DC: Response of a yeast glycogen synthase gene to stress. Mol Microbiol I 995, I6(6): I 197-1205.

30. Parrou JL, Enjalbert B, Francois J: STRE- and cAMP-independent transcriptional induction of Saccharomyces cerevisiae GSY2 
encoding glycogen synthase during diauxic growth on glucose. Yeast 1999, I5( I 4): | 47|-| 484.

31. Rowen DW, Meinke M, LaPorte DC: GLC3 and GHAI of Saccharomyces cerevisiae are allelic and encode the glycogen branching enzyme. Mol Cell Biol I992, I 2(I):22-29.

32. Teste MA, Enjalbert B, Parrou JL, Francois JM: The Saccharomyces cerevisiae YPR I84w gene encodes the glycogen debranching enzyme. FEMS Microbiol Lett 2000, 193(1): 105-IIO.

33. Unnikrishnan I, Miller S, Meinke M, LaPorte DC: Multiple positive and negative elements involved in the regulation of expression of GSYI in Saccharomyces cerevisiae. J Biol Chem 2003, 278(29):26450-26457.

34. Clancy MJ, Smith LM, Magee PT: Developmental regulation of a sporulation-specific enzyme activity in Saccharomyces cerevisiae. Mol Cell Biol 1982, 2(2): I7|-I78.

35. Ball CA, Jin H, Sherlock G, Weng S, Matese JC, Andrada R, Binkley G, Dolinski K, Dwight SS, Harris MA, et al:: Saccharomyces Genome Database provides tools to survey gene expression and functional analysis data. Nucleic Acids Res 200I, 29(I):80-8I.

36. Faccioli P, Ciceri GP, Provero P, Stanca AM, Morcia C, Terzi V: A combined strategy of "in silico" transcriptome analysis and web search engine optimization allows an agile identification of reference genes suitable for normalization in gene expression studies. Plant Mol Biol 2007, 63(5):679-688.

37. Lee S, Jo M, Lee J, Koh SS, Kim S: Identification of novel universal housekeeping genes by statistical analysis of microarray data. J Biochem Mol Biol 2007, 40(2):226-23I.

38. Wenzel TJ, Teunissen AW, de Steensma HY: PDAI mRNA: a standard for quantitation of mRNA in Saccharomyces cerevisiae superior to ACTI mRNA. Nucleic Acids Res 1995, 23(5):883-884.

39. Choder M: A general topoisomerase I-dependent transcriptional repression in the stationary phase in yeast. Genes Dev 199I, 5(I 2A):2315-2326.

40. Choder M, Young RA: A portion of RNA polymerase II molecules has a component essential for stress responses and stress survival. Mol Cell Biol I993, I3(I I):6984-699I.

4I. Monje-Casas F, Michan C, Pueyo C: Absolute transcript levels of thioredoxin- and glutathione-dependent redox systems in Saccharomyces cerevisiae: response to stress and modulation with growth. Biochem J 2004, 383(Pt I): I39-I47.

42. Rosenberg S, Coit D, Tekamp-Olson P: Glyceraldehyde-3-phosphate dehydrogenase-derived expression cassettes for constitutive synthesis of heterologous proteins. Methods Enzymol 1990, I85:34I-35I.

43. Kingsman SM, Cousens D, Stanway CA, Chambers A, Wilson M, Kingsman AJ: High-efficiency yeast expression vectors based on the promoter of the phosphoglycerate kinase gene. Methods Enzymol 1990, 185:329-34I.

44. Hinnen A, Buxton F, Chaudhuri B, Heim J, Hottiger T, Meyhack B, Pohlig G: Gene expression in recombinant yeast. Bioprocess Technol 1995, 22:121-193.

45. Mumberg D, Muller R, Funk M: Yeast vectors for the controlled expression of heterologous proteins in different genetic backgrounds. Gene 1995, I56(I): I I9-122.

46. Nacken V, Achstetter T, Degryse E: Probing the limits of expression levels by varying promoter strength and plasmid copy number in Saccharomyces cerevisiae. Gene 1996, I75(12):253-260

47. Graham IR, Chambers A: Constitutive expression vectors: PGK. Methods Mol Biol 1997, 62:159-169.

48. Chambers A, Packham EA, Graham IR: Control of glycolytic gene expression in the budding yeast (Saccharomyces cerevisiae) Current Genetics 1995, 29(I): I.

49. Wang Z, Wilson WA, Fujino MA, Roach PJ: Antagonistic controls of autophagy and glycogen accumulation by Snflp, the yeast homolog of AMP-activated protein kinase, and the cyclindependent kinase Pho85p. Mol Cell Biol 200I, 2 I ( I 7):5742-5752.

50. van Dijken JP, Bauer J, Brambilla L, Duboc P, Francois JM, Gancedo C, Giuseppin ML, Heijnen JJ, Hoare M, Lange HC, et al:: An interlaboratory comparison of physiological and genetic properties of four Saccharomyces cerevisiae strains. Enzyme Microb Technol 2000, 26(9-10):706-7|4.

5I. Guillou V, Plourde-Owobi L, Parrou JL, Goma G, Francois J: Role of reserve carbohydrates in the growth dynamics of Saccharomyces cerevisiae. FEMS Yeast Res 2004, 4(8):773-787.
52. Parrou JL, Francois ]: A simplified procedure for a rapid and reliable assay of both glycogen and trehalose in whole yeast cells. Anal Biochem 1997, 248(I): 186-188.

53. Pfaffl MW: A new mathematical model for relative quantification in real-time RT-PCR. Nucleic Acids Res 200I, 29(9):e45.
Publish with Biomed Central and every scientist can read your work free of charge

"BioMed Central will be the most significant development for disseminating the results of biomedical research in our lifetime. "

Sir Paul Nurse, Cancer Research UK

Your research papers will be:

- available free of charge to the entire biomedical community

- peer reviewed and published immediately upon acceptance

- cited in PubMed and archived on PubMed Central

- yours - you keep the copyright 